\title{
SCIENCE
}

NEW YORK, MAY $27,1892$.

\section{A KEY TO THE MYSTERY OF THE MAYA CODICES.}

I wISH to announce through Science to those interested in the subject, that I have fortunately discovered, at last, the key which will unlock the mystery of the Maya Codices and, probably, of the Central American inscriptions. The progress of decipherment will be slow, but, the clue having been obtained, it will ultimately be accomplished. I have already determined the signification of some dozens of characters and in several instances ascertained the general sense of a group forming a sentence.

This discovery settles at the same time several other points. First, it shows that the direction in which the Codices are to be read is as assumed by me in the "Study of the Manuscript Troano," pp. 136-141. Second, that the parts of the compound characters are to be read chiefly in the same way;

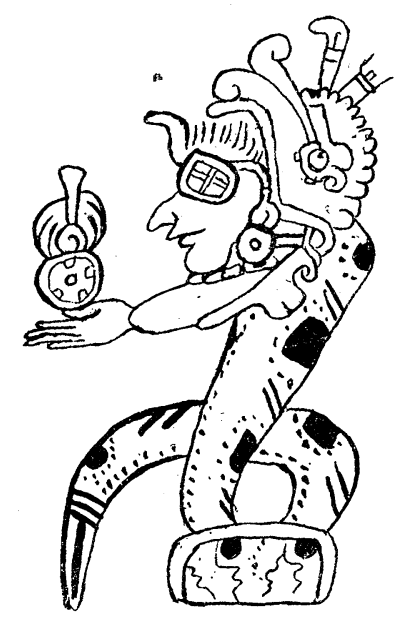

that is, from left to right and from the top downward. It shows, in the third place, that, although there are a number of conventional symbols, yet the great majority of the characters are truly phonetic, and the writing of a bigher grade than has been hitherto supposed. Last, it shows that, after all, Landa's statements in regard to the mode of writing and the letters and characters are, to a large extent, correct. For example, his second $b$ is correct if a central dot is inserted, giving five instead of four. His $c$ is also correct, as are his $e, i$, and $c a$, his $k, k u, z, h a, m a$, and sign of aspiration. The $l$ as given in his example of the mode of writing is correct. His first $x(\mathrm{dz})$, if placed horizontally and slightly modified, is the symbol for $c h$ '.

Landa's trouble as to the Maya mode of spelling, where he assumes that $l e$ is written thus, ele, arises from the fact that the beginning of the symbol for $l$ is so nearly like that for $e$, that he has mistaken one for the other, thus considering the first part of the $l$ as an $e$. This can be shown, as symbols for the same word, having the same meaning, are found at one point in the Codex Troano.
As one result of this discovery, I will introduce here an example, with illustration from page 32 of the Cortesian Codex. In the figure here shown the reader will observe a character in the hand of the human being represented as grasped in the mouth of the serpent and also one from which the serpent seems to rise. The latter is the symbol for $c a b$, which in the Maya language signifies both earth and honey, here undoubtedly earth. The one in the hand of the human figure is a compound symbol for yeb or yeeb, signifying mist, dew, or humidity. We also observe in the eye of the human head a cross, which, like the serpent, is a rain or moisture symbol; thus agreeing with the view which has been advanced in regard to the signification of these symbols.

Without further reference at present to the discovery, I may say that I am preparing specimens of my interpretations and explanations, to be submitted to some of our leading archæologists and linguists.

In concluding, allow me to say that if I am correct in the above deductions, which have been reached after careful examination and tests, the Bureau of Ethnology, of which I have the honor to be a member, may claim to have rendered probable the solution of two important questions relating to the pre-Columbian times of our continent, to wit: Who were the mound builders? and, What is the significance of these curious Central American inscriptions and Maya writings?

Washington, May 17.

Cyrus Thomas.

\section{DR. D. H. STORER'S WORK ON THE FISHES.}

Such of Dr. Storer's papers as have come to my notice, some of the minor articles possibly being overlooked, indicate that his activity as an ichthyologist extended over a period of about thirty years, beginning about 1836. His list of publications on the fishes is not a loug one, and his standing amongst the workers of his own period, or of later periods, in this department of science, may be determined entirely from the latest, his greatest work, "The History of the Fishes of Massachusetts."

1. The earliest paper noted is entitled "An Examination of the "Catalogue of the Marine and Fresh-Water Fishes of Massachusetts,' by J. V. C. Smith, M.D.," in Professor Hitchcock's "Report on the Geology, Mineralogy, etc., of Massachusetts." This appeared in Vol. I. of the Boston Journal of Natural History, pp. 347-365, pl. viii., occupying some eighteen pages, and bearing date of May, 1836.

2. In July, 1839, he published his "Remarks on the 'Natural History of the Fishes of Massachusetts,' by J. V. C. Smith, M.D.," in Vol. XXXVI. of Silliman's American Journal of Science and Arts, pp. 337-349, previously read before the Boston Society of Natural History at its meeting on March 20 of the same year.

3. His Reports on the Ichthyology and Herpetology of Massachusetts make an octavo of 253 pages and three plates. This was issued in connection with the report on the Birds, by Mr. Peabody. The Report on the Fishes was also pub- 